\title{
DANÇAS EM TERREIROS: educação dos corpos para as giras na Quimbanda
}

\author{
Rodrigo Lemos Soares \\ Mauro Dillmann
}

\section{Resumo}

As danças, em terreiros, são elementos constituintes de caracteres específicos de expressividade, elas reiteram identidades. $\mathrm{O}$ artigo em questão problematiza a educação dos corpos em relação às danças de exus e pombagiras, em terreiros de Quimbanda, na cidade do Rio Grande / Rio Grande do Sul. Utilizamos, para tanto, conceitos como educação dos corpos e danças, para discutir sobre essas manifestações em terreiros de Quimbanda. As danças em terreiros, especificamente as de exus e pombagiras, estão vinculadas com noções acerca do que significa ser um sujeito religioso, que pertence a um local específico, uma expressividade religiosa. Dançar, a partir das mitologias dos exus ou das pombagiras, é aqui entendido como acontecimento sociocultural, que tem por base noções de pertencimento. $O$ aporte teórico desse texto está centrado nos estudos culturais, na sua vertente pós-estruturalista e as narrativas foram produzidas a partir de entrevistas estruturadas, sendo os dados observados sob uma análise cultural. Consideramos, então, que as danças compõem o aparato ritualístico dos terreiros; além disso, elas não possuem caráter único e sinalizam produções de identidades. Assim, especifica-se que dançar, nesses locais, é uma manifestação simbiótica entre entidades e sujeitos, a qual resulta em uma forma de expressão da religiosidade.

Palavras-chave: educação dos corpos; dança; Quimbanda

DANCES IN TERRACES: education of bodies for the spinners at Quimbanda

\begin{abstract}
Dances, in terraces, are constituent elements of specific characters of expressiveness, they reiterate identities. The article in question problematizes the education of bodies in relation to the dances of exus and pombagiras, in terraces of Quimbanda, in the city of Rio Grande / Rio Grande do Sul. We used, for this, concepts such as education of bodies and dances, to discuss these manifestations in Quimbanda terraces. Dances in terraces, specifically, exus and pombagiras, are linked with notions about what it means to be a religious subject, who belongs to a specific place, a religious expressiveness. Dancing, from the mythologies of the exus or pombagiras, is understood here as sociocultural events, which is based on notions of belonging. The theoretical contribution of this text is centered on the cultural studies, in its post-structuralist aspect and the narratives were produced from structured interviews, the data being observed under a cultural analysis. We consider, then, that the dances, make up the ritualistic apparatus of the terraces, in addition, they have no unique character and signal productions of identities. Thus, we specify that dancing in these places is a symbiotic manifestation between entities and subjects, which results in a form of expression of religiosity.
\end{abstract}

Keywords: education of bodies; dance; Quimbanda

DANZAS EN TERREIROS: educación de los cuerpos para los hilanderos en Quimbanda

Resumen

Las danzas, en terreiros, son elementos constitutivos de caracteres específicos de expresividad, reiteran identidades. El artículo en cuestión problematiza la educación de los cuerpos en relación con las danzas de exus y pombagiras, en terreiros de Quimbanda, en la ciudad de Rio Grande / Rio Grande do Sul. Usamos, para esto, conceptos como la educación de cuerpos y danzas, para discutir estas manifestaciones en terreiros 
de Quimbanda. Las danzas en terreiros, específicamente las de exus y pombagiras, están vinculadas con nociones sobre lo que significa ser un sujeto religioso, que pertenece a un lugar específico, una expresividad religiosa. El baile, basado en las mitologías de los exus y pombagiras, se entiende aquí como un evento sociocultural, basado en nociones de pertenencia. El aporte teórico de este texto se centra en los estudios culturales, en su vertiente postestructuralista y las narrativas fueron producidas a partir de entrevistas estructuradas, observándose los datos bajo un análisis cultural. Consideramos, entonces, que las danzas constituyen el aparato ritualista de los terreiros; además, no tienen un carácter único y señalan la producción de identidades. Así, se especifica que bailar en estos lugares es una manifestación simbiótica entre entidades y sujetos, lo que se traduce en una forma de expresión de religiosidad.

Palabras clave: educación de los cuerpos; danza; Quimbanda

\section{SITUANDO OS PONTOS E AQUECENDO OS CORPOS...}

O presente artigo é parte de uma dissertação que foi produzida no Programa de Pósgraduação de História da Universidade Federal do Rio Grande, e teve como objetivo investigar de que maneira as relações entre pedagogias e ensino dos movimentos / danças de entidades espirituais do universo religioso são desenvolvidas em terreiros de Quimbanda ${ }^{1}$ da cidade do Rio Grande / Rio Grande do Sul (RS). Para tanto, analisaram-se narrativas de seis sujeitos, quatro homens e duas mulheres, todos(as) residentes no município de Rio Grande / RS. O material foi produzido a partir da metodologia de investigação narrativa (CONNELLY, CLANDININ, 1995) com o uso de questionários individuais como ferramenta para a produção de dados, a partir de um roteiro preestabelecido (FLICK, 2009). Para esse estudo, estabeleceram-se conexões com os estudos culturais (NELSON, TREICHLER, GROSSBERG, 1995), na sua vertente pósestruturalista e em perspectiva de análises culturais (BARBOSA, 1995) das narrativas.

As análises foram produzidas, a partir de cinco fases: realização das entrevistas; transcrição; agrupamento por aproximação de significado; categorização. A primeira fase se refere ao encontro com os sujeitos de pesquisa, quando se produziu uma identificação inicial, além das respostas ao roteiro de entrevistas. Nesse momento, os entrevistados(as) assinaram os termos de consentimento livre e explicativo. A segunda fase foi a de transcrição das entrevistas. Os primeiros textos narrativos, oriundos desse momento, foram enviados aos(as) participantes para que eles(as), caso julgassem necessário, modificassem os dados produzidos, realizassem alguma correção ortográfica, bem como analisassem os usos das narrativas e depois retornassem ao pesquisador. Assim, encaminhou-se a terceira fase, quando foi executado um agrupamento das questões e intervenções.

Em seguida, retomaram-se as leituras dos dados e grifados os pontos convergentes em cada questão. Alguns dados se aproximavam, mas em questões diferentes; sendo assim, foram direcionados aos agrupamentos aos quais havia maior proximidade, apontando que eram de outras questões. Posterior ao agrupamento, as narrativas foram novamente lidas e, a partir da aproximação significativa, elaboradas duas categorias, denominadas recorrências e escapes. Na primeira, agruparamse os dados que se aproximavam, recorrentes nas entrevistas. Na segunda, os escapes, referiam-se às narrativas que se distanciavam do objetivo geral, mas que mantinham relação com a pesquisa, ou seja, de alguma forma discorriam sobre noções e relações com as danças ou, neste caso, em específico, tratavam da identificação tanto com a religiosidade quanto com a pesquisa em si.

Este recorte teve por objetivo investigar como a educação dos corpos ocorre, no sentido de compreender as danças de exus e pombagiras nos terreiros dos(as) participantes da pesquisa. Assim, o texto abarca discussões contingentes referentes às danças nos terreiros. Desse modo, destaca-se que esse texto refere-se às recorrências. Outro ponto é o fato de que não será tratado aqui

${ }^{1}$ Para um primeiro acesso ao que se assumo por Religiosidade e Quimbanda indicam-se as leituras de Soares, Dillmann, 2020; Soares, 2018, textos nos quais, também, sustentam-se as argumentações dessa escrita. 
de dança de/em/nos terreiros como sinônimo para danças afro, embora em alguns momentos se fale desse estilo de dança, pelo fato de ele aparecer como mais próximo à temática do estudo proposto. Não se comete tal ato por não se enxergarem aproximações óbvias entre ambos, pois, para isso, precisariam ser ampliadas as discussões em torno do conceito de negritude, além de abranger debates acerca de entendimentos sobre manifestações religiosas de matriz / vertente africana, entre outros termos, os quais não são objeto desse texto. Deixa-se em suspenso essa problematização que será sanada em outro momento.

Educação dos corpos, ensaiando as giras...

Somos educados o tempo todo por diferentes mecanismos e sujeitos, e essa educação, nessa pesquisa, está sendo assumida como produtora de corpos, uma vez que ela age sobre eles, os corpos (FOUCAULT, 1995). Desse modo, amplia-se a escrita dizendo que é nos corpos que presenciamos, visualizamos as escrituras, as cicatrizes e registros dos tempos e acontecimentos (GIANNATTASIO, 2012). Assim, as marcas corporais possibilitam pistas de nossos locais de origem, de nossas experiências e nos posicionam, através das linguagens, por meio das identidades a eles conferidas, em lugares de sujeitos específicos (GOELLNER, 2007). Tal assertiva, porém, não implica fixidez. E é nessa direção que a educação em terreiros, no caso dessa pesquisa, por meio do ensino de danças de exus e pombagiras, está assentada em visões ampliadas de corpo, as que escapam à noção única de objeto material orgânico, biológico.

Para Giannattasio (2012, p. 19) as sociedades conferem aos corpos diferentes funções: “[...] a ele se vinculam, por exemplo, todas as formas de ascetismo, a querela nas relações entre matéria e espírito até às dimensões da cultura e da linguagem". Atrelam-se aos corpos diferentes mecanismos e tecnologias, como as cirurgias plásticas, por exemplo, correspondentes a tempos específicos, que possuem como função moldá-los, educá-los, a anseios que tendem a corresponder a normativas sociais vigentes. Em Foucault (1995) é sobre os corpos que se exercem os controles sociais e, por isso, eles precisam ser disciplinados.

É por meio dos corpos que as danças são apresentadas nessa pesquisa e, por isso, elas, as danças, possuem caracteres de pedagogias específicas dos terreiros. Dito isso, salienta-se que se trata de uma noção de corpo que é produzido nos/pelos/para os ritos de uma religiosidade, a Quimbanda. Desse modo, ao dizer dessa origem, de pensamento, pelo menos, já se anuncia o lugar ou lugares de onde se fala (SOARES, DILLMANN, 2020; SOARES, 2018). Articulam-se a essas arguições as seguintes narrativas (respostas dos sujeitos da pesquisa, em ordem de retorno):

[...] Acho que aí está uma das funções da religião, educar as pessoas, seja para vida, para os cultos, para o que ela quiser, tu vai mediar a vida delas quando passa a ser mãe ou pai de santo. Quando tu assume esse compromisso, ele é um compromisso que não podes passar adiante, a menos que a pessoa saia da tua casa. A minha preocupação é que as pessoas saiam daqui melhor do que chegaram, mas sabendo que as minhas regras são essas, rígidas, daí elas fazem o que quiserem com isso. (DAIANE da MARIA QUITÉRIA, 23 maio 2018).

[...] Tem gente que tem uma visão errada da religião, daí chega aqui achando que pode qualquer coisa. Cada filho tem uma função e é preparado para isso, cada coisa tem seu tempo, sua hora, depois de aprender como é a coisa, eles começam a fazer suas funções. Tu precisa saber que a casa tem um fundamento e é isso que vai te permitir a evolução espiritual, a dançar com as tuas entidades. (ROBERTO do PANTERA NEGRA, 24 maio 2018).

[...] Não é qualquer coisa. A pessoa quando vem para tua casa de religião precisa seguir tuas regras, as regras da casa, porque tu já tem uma lógica e já educou teus filhos a seguirem uma doutrina, fundamento. A pessoa precisa chegar e saber 
como funciona, óbvio, tem gente que já vem de outras casas, mas daí temos que ensinar como é aqui. (DANIEL da PADILHINHA, 27 maio 2018).

[...] Eu ensino tudo que acho necessário aqui do terreiro. Preparo cada pessoa para seguir sua vida espiritual e, nisso, é óbvio que tu molda as pessoas como tu queres, o que não é fácil, porque muitas vêm de outras casas, com vícios, trejeitos, condutas e expressão das entidades, mas isso que é legal, tu poder mostrar outras formas de viver a religião, pelo menos no meu caso, sem dizer que uma é certa e a outra é errada, mas que é do teu jeito, da maneira como a tua casa funciona. (MARCELO do TRANCA RUAS DAS ALMAS, 14 jun. 2018).

[...] cada ritual tem um ensinamento que tu precisa saber, para depois passar para outro nível, não tem como pular de uma coisa para outra se o teu fundamento não estiver bem sólido. Tua entidade não vai chegar e dançar, se tu não consegue entender o que está acontecendo com o teu corpo naquele momento. (JOSÉ CARLOS do MAIORAL, 16 jun. 2018).

[...] Os fundamentos da casa são ensinados para os médiuns que querem aprender. Tem os cruzamentos, os segredos, as rotinas do terreiro que não são passadas de qualquer jeito, tudo tem que sentir vontade de aprender, querer saber, e daí eu ensino quando vejo que o filho está pronto para receber tal fundamento. (DIONE da MARIA PADILHA DAS ALMAS, 16 jun. 2018).

A partir das narrativas dos(as) participantes, propõe-se um diálogo com Michel Foucault (2007b, p. 22) ao escrever que o corpo, “[...] lugar de dissolução do eu, volume em perpétua pulverização, traz consigo em sua vida e em sua morte, em sua força e em sua fraqueza a inscrição de acontecimentos e conflitos, erros e desejos". Esse pensamento pressupõe uma relação de alteridade, tendo em vista que a pedagogização ocorre pelas relações com outros sujeitos. O contato com o outro é uma ação sinestésica. Da sinestesia entre sujeitos e, por sua vez, corpos possibilitam que se operem os "micropoderes ou subpoderes" (MACHADO, 2006, p. 168) e, por eles, somos educados. Contudo, é preciso atender ao fato de que, uma "[...] ação não age diretamente e imediatamente sobre os outros, sobre corpos, mas que age sobre a ação" (FOUCAULT, 1995, p. 243). Nossos trejeitos é que são treinados, forjando corpos disciplinados ou se diria, educados / pedagogizados.

Assim, reitera-se que o corpo não é um elemento inerte ao poder. Antes disso, por estar presente em uma relação dinâmica, ele potencializa relações de poder. Isso decorre das afirmativas com relação às resistências de corpos que já chegam nos terreiros, vindos de outras casas, ensinados, mas que a partir desse momento, receberão outras pedagogias. No entanto, Foucault (1995, p. 243) escreve que "[...] isso não significa que a relação de poder entre polos ativos não deixe marcas nos corpos, mas que a análise não está focada sobre a coação direta e mecânica de um corpo sobre outro", ou como expressaram os sujeitos da pesquisa, tudo leva tempo, tem sua hora, são processos.

Desse modo, salienta-se que os corpos e suas produções, significações estão envoltos por redes socioculturais de sentidos históricos, postos em cheque, quando em relação com meios culturais de circulação específicos, como no caso dos terreiros, nos quais os corpos são construídos a partir de mitos, ritos e rituais que inscrevem caracteres nesses corpos e que, assim fazendo, produzem identidades. Recorre-se ainda a Foucault (1997a, p. 28-29) ao escrever que os corpos estão mergulhados em campos políticos e que é este saber que possibilita o desenvolvimento das chamadas "[...] tecnologias políticas dos corpos", sob as quais os corpos são educados, a partir de saberes específicos dos locais, ou como expresso nas narrativas, pelos fundamentos dos terreiros. Através de uma noção tecnológica é possível que se compreenda o exposto pelo autor, visto que, para ele "[...] o corpo é aquilo que muda, cresce, degenera, morre, vibra, dobra-se, ajusta-se, explode" (FOUCAULT, 1997a, p. 29) e, por isso, ele é instável, suscetível a mudanças e ao 
modificá-lo, recorrendo a tecnologias de cada cultura, tem-se em mãos outras formas de saber. Os corpos são, então, ao mesmo tempo, local onde os efeitos do poder se inscrevem e território de resistência. Assim, as figuras corporais são produzidas, por meio de processos educativos, engendrados em mecanismos de poder.

Aliado a esse pensamento sobre educação dos modos corpóreos, percebem-se os processos de ensino de danças, como pedagogias culturais que agem sobre os corpos, orientadas por processos de objetivação e subjetivação. É durante o ensino e pós-pedagogização que os sujeitos vinculam-se a uma identidade ou a um conjunto delas, assumindo-as como sua, por meio de inscrições de diferentes signos, em seus corpos. Corporificam-se, então, as ideias de Le Breton (2006) e Goellner (2010), ao escreverem que o corpo é o que somos, não existe terceira pessoa. Segundo esses dois estudos, ao se narrar uma sociologia do corpo é de nós mesmos que falamos. Fazer referência aos corpos, é referirmo-nos não apenas à materialidade biológica que os constitui, mas ao conjunto de esquemas socioculturais que nos constituem. E, desse modo, daríamos fim às dicotomizações “[...] corpo-alma, interioridade-exterioridade, mente-cérebro" (ORTEGA, 2006, p. $42)$.

Para encerrar essa parte, recorre-se a Ortega (2006), quando o autor expõe que somos o que aparentamos ser, e que tal feito se deve aos modos como exteriorizamos nossos corpos e incorremos às liberdades de/para produzi-los. Assim, faz-se uso das pesquisas de Figueira (2003) e Quadrado (2007), para posicionar os corpos como produções biossociais construídas em processos discursivos e, desse modo, perceber "[...] sua provisoriedade e as infinitas possibilidades de modificá-lo, aperfeiçoá-lo, significá-lo e ressignificá-lo" (FIGUEIRA, 2003, p. 126). Isso porque não se está falando de "[...] algo dado a priori [que] nem mesmo é universal" (GOELLNER, 2007, p. 28) mas, sim, se está tratando de produtos constituídos "[...] na e pela linguagem, destituindo-as dos locais de verdade e fixidez" (GOELLNER, 2007, p. 29) para os quais “[...] a anatomia deixa de ser um destino para ser uma escolha" (LE BRETON, 2003, p. 49).

Ao utilizar essas passagens dos(as) autores(as), anuncia-se a relação entre o corpo e a pesquisa, no sentido de que estão imbricados na confecção dessa escrita. As danças, os terreiros, as religiosidades, assim como os corpos, não escapam à história, necessitando do estabelecimento de relação direta, por meio da qual um necessitará do outro para existir. Os corpos, assim, são identidade, cultura, história, biologia, maquinaria, são as representações que se criam sobre ele; corpo é poder, controle, é o que dele se diz. É nos corpos que se entende serem possíveis as manifestações das religiosidades, especificamente das danças ensinadas nos terreiros de Quimbanda; parte-se desse entendimento para compreender os saberes imbricados nas danças de exus e pombagiras.

Entre danças e saberes: as giras dos terreiros...

Inicia-se o exercício de escrita desse subitem recorrendo a Eduardo Miranda (2014), quando escreve que as danças em terreiros não enquadram, classificam um sujeito como adepto de um estilo, mas como um(a) mantenedor(a) de elementos culturais de um lugar específico, no caso dessa vertente religiosa, de ancestralidades ou, mais especificamente, de hibridentidades, tendo em vista que a Quimbanda é fruto de diferentes processos culturais. As danças em terreiros são, nesse sentido, modos de expressar culturas de locais, que se manifestam em "[...] corpos-territórios" (MIRANDA, 2014, p. 159). Assim como as demais manifestações culturais abarcadas em solo brasileiro, as danças desenvolvidas ou executadas pelos(as) praticantes da Quimbanda apresentam caracteres referentes, em princípio, às entidades daqueles locais. Esse fator, por sua vez, não fere, mas enriquece os cultos aqui praticados, a partir das múltiplas manifestações de dança, música, vestimentas e mesmo ritos. Para Miranda (2014, p. 148), dançar, a partir da religiosidade da matriz 
/ vertente africana, "[...] solicita ações corporais que transmudem o óbvio e assumam formas circulares e tenha o chão como ingrediente somatório na composição das danças".

Nesse excerto, encontram-se duas das características da cultura afro, a da ritualidade dos pés no chão ${ }^{2}$ e uma presença corporal. Tendo apresentado essa passagem, arrisca-se a dizer que as expressões da cultura corporal das religiosidades afro-brasileiras são um exemplo de vivência das corporeidades, por meio da dança. Em Santin (2003, p. 68), a corporeidade e os estudos do corpo, pela Antropologia, abrangem toda a ação humana, da qual "[...] o gesto e a palavra são os amplificadores do universo significativo, isto é, do universo humano. O corpo e seus movimentos estão sempre no centro de toda e qualquer manifestação e possibilidade expressiva".

Apresentam-se, então, amarrando-as com as reflexões acima realizadas, as narrativas dos(as) participantes da pesquisa para propor diálogos sobre as danças nos terreiros de Quimbanda. As respostas, nesse momento, foram dirigidas às questões: o que entendes por dança? Ela está no terreiro? Se sim, qual(quais) os usos / atribuicõoes dela no terreiro? Segundo os sujeitos do estudo, é consenso a presença das danças em seus terreiros, no entanto, os entendimentos, usos e atribuições foram considerados de modos distintos, conforme apresentado a seguir:

[...] Dança é expressão, movimento, são as histórias das entidades em movimento; também significa a energia da vibração do terreiro. Aqui em casa ela é usada para fazer os rituais, ela compõe nossas práticas da casa. Pelas danças tu mostra muitas coisas, como as expressões das entidades, se elas estão bem ou não, mas tudo isso depende também de como os filhos estão [...] a dança é sempre um fundamento do terreiro. (DAIANE da MARIA QUITÉRIA, 23 maio 2018).

[...] Dança é gesto, é a expressão das entidades e das histórias dos médiuns. São movimentos que envolvem médium e assistência; pela dança as pessoas ficam encantadas, também. No terreiro, tu usa as danças para tudo. Não tem prática de terreiro sem danças, porque dança é energia, é manifestação das energias das entidades nos corpos dos médiuns. (ROBERTO do PANTERA NEGRA, 24 maio 2018).

[...] Dança é tudo de maravilhoso, cada um pode dar um nome, mas só vejo beleza, conexão com as entidades, com as energias espirituais do terreiro. Pelas danças, ensino os filhos a compreenderem suas entidades, as energias delas, tudo isso, pelas histórias dos exus e pombagiras; sem dança parece que falta energia no terreiro, mas tem rituais sem dança, mas tudo isso a gente faz ensinando os filhos da casa, educando cada médium, partindo da mitologia das entidades, dos símbolos delas, das histórias dos nossos ancestrais. (DANIEL da PADILHINHA, 27 maio 2018).

[...] A dança é o encanto da casa, é a magia das entidades que circulam fazendo emanar coisas boas; mas pode ser dito outras coisas com a dança, por exemplo, pode significar alegria, tristeza, batalha, guerras, as forças da natureza; dependendo da entidade, bravura, carinho, abraço, além de ser um convite para dançar, porque quando tocam os tambores e as entidades começam a dançar é quase impossível não querer girar a dança deles, e ainda tem as entidades que te chamam para girar junto, que significa limpeza ou mesmo um convite à incorporação. Como te disse, a dança é tudo aqui em casa, é o encanto do terreiro, a sessão fica forte, firme, e os fundamentos da casa aparecem. (MARCELO do TRANCA RUAS DAS ALMAS, 14 jun. 2018).

[...] A dança é a manifestação das energias das entidades. Um médium forte e pronto deixa fluir essa energia e dança, gira. A dança está nos rituais da casa,

\footnotetext{
${ }^{2}$ Ainda que tenha conferido esse destaque, precisa-se escrever sobre as possibilidades de se encontrar, em terreiros, sujeitos que incorporam entidades com os pés calçados como, por exemplo, usando sapatos, sapatilhas, entre outros.
} 
significa o movimento dos trabalhos, a energia circulando entre todos que estão na corrente e visitando. (DIONE da MARIA PADILHA DAS ALMAS, 16 jun. 2018).

[...] A dança é a manifestação das entidades, a energia delas que se materializa nos corpos dos médiuns. Ela faz parte dos rituais da casa, é a energia que potencializa o trabalho e firma forte no corpo do médium. (JOSÉ CARLOS do MAIORAL, 16 jun. 2018).

Segundo Guerra (2008, p. 1), na religiosidade africana se “[...] dança nos diversos eventos da comunidade a que pertence e das mais variadas formas que a criatividade e a espiritualidade lhe concedem, mas, especialmente para celebrar a vida!". Ainda em Guerra (2008, p. 2) a cultura corporal africana manifesta-se na "[...] dança, corpo, movimento, sons, ritmos, palavras, contagiando e penetrando no seu eu e nos outros seres a sua volta, o ímpeto mais sublime de 'energia vital' que no Brasil é chamado de Axé'.

Souza (2000) escreve que, nas religiosidades, as danças são caracterizadas pela função que exercem de não impressionar o público, mas de demonstrar um sentido para a vida terrena, dos(as) fiéis, através da síntese dos gestos e movimentos, seja de entidades, como exus e pombagiras ou dos orixás. Já, nas danças afro de palco ${ }^{3}$, uma boa parte de seu conteúdo e da sua forma sofre com uma considerável criatividade para causar impressão e, quando os mitos são representados e interpretados por um(a) solista, isto é, um(a) único(a) dançarino(a) - ator / atriz em cena -, a dança poderá ser executada por improvisos.

Retomando a discussão para o centro da pesquisa, a dança "[...] que é de transe, adquire um duplo papel: de um lado dá-se a demonstração da experiência mística do fiel na transformação interior, do outro, por meio dos passos das coreografias, conta a história mítica e revela a visão de mundo do grupo" (BARBARA, 2002, p. 2). A dança, para essa autora, não é, pelo menos por princípio cultural e simbólico, “[...] uma repetição automática de gestos ou de coreografias, mas uma nova experiência do corpo, um corpo que passou por todo um processo ritual" (BARBARA, 2002, p. 8). As danças de vertentes religiosas africanas buscam, segundo a autora, representar histórias e mitologias, no entanto, elas sofrem com as interferências das vidas dos(as) praticantes, para além dos terreiros, logo, esse princípio nem sempre será executado. Além disso, embora possuam caracteres específicos de cada entidade que representa (segundo a crença religiosa dos(as) participantes), para que os mesmos ocorram faz-se necessária uma adaptação a um corpo específico, o que não fere a dança ou mitologia representada, mas expõe as diferenças entre os mundos mitológicos e as vivências cotidianas do hoje.

A música e a dança como parte integrante do cotidiano das religiões de matriz africana e a presença do candomblé observável no dia a dia, nos cantos (onde ofereciam serviços), nas lojas (onde habitavam coletivamente), ou nos terreiros (onde cultuavam seus deuses) demarcam identidades e produzem marcas corporais nos sujeitos praticantes (GUERREIRO, 2010). Desse modo, pode-se perceber o quanto as danças são influenciadas pelas culturas regionais em que os terreiros e seus praticantes estão inseridos.

Barbara (2002) demarca que, ao ocorrer desse modo, a dança em si não acontece por repetições, mas sim por leituras possíveis, ou seja, transcrições corporais que ocorrem variando de um corpo para o outro, isto é, mesmo que dois sujeitos sejam regidos(as) por uma mesma entidade ou orixá, eles(as) possivelmente dançarão de modos distintos. Para Machado (2014, p. 21), “[...] a dança, portanto, faz parte de uma concepção muito maior de movimento que só pode ser pensada a partir das cosmologias respectivas".

\footnotetext{
${ }^{3}$ Essa diferenciação está demarcada tendo em vista que, para Souza (2000), essas danças possuem, de fato, funções distintas. Para além de seus locais de execução, os sentidos a elas conferidos também são outros.
} 
Machado (2014) escreve, então, que no âmbito das religiões afro-brasileiras, por exemplo, a dança é um elemento crucial. Ela não está separada da cosmovisão inerente aos sistemas de pensamento africano, para os quais os sujeitos são seres globais e não fragmentados. Assim, os pares corpo e espírito, corpo e pensamento não se dão como termos opositivos e descontínuos, como na cultura ocidental de matriz cristã (MACHADO, 2014).

Segundo Cardoso (2006), um exemplo possível para compreender essas danças seria a de Ossain ${ }^{4}$. Para ele, os movimentos, as expressões contidas na coreografia desse orixá imitam alguém bebendo algo, seriam os remédios que esta santidade plantou. Porém, os movimentos dependem das letras entoadas: “[...] os gestos coreográficos, no decorrer da dança, seguem o significado contido na letra da canção [...]" (CARDOSO, 2006, p. 248). Isso porque "[...] no candomblé, mito, dança e música, estão intimamente interligados" (CARDOSO, 2006, p. 250).

$\mathrm{Na}$ relação música-instrumental-dança, o rum ${ }^{5}$ emite frases musicais que podem ser tanto uma resposta a uma determinada frase coreográfica quanto um pedido para que se faça uma frase coreográfica. Essas frases coreográficas, por sua vez, são representações dramáticas, são gestos que imitam as características das entidades, principalmente, as ditadas nas mitologias. Os instrumentos percussivos, a ginga sonora, a simbologia das danças e coreografias e os grafismos estão espalhados pelo cenário (o terreiro), onde o corpo é uma das ferramentas dessa construção (FILHO, 2016). Por essa razão, considera-se importante o conhecimento dos mitos das entidades, pois por intermédio deles passamos a compreender os significados contidos nas frases coreográficas.

Aliamo-nos, então, à ideia defendida por Strazzacappa (2001), ao mencionar que a música e a dança, para além de estarem associadas, sofrem influências das regiões específicas onde se desenvolvem, porém são componentes das culturas locais dos povos. No entanto, para Cuche (1998), esses costumes, hábitos ou valores somente podem ser compreendidos se forem relacionados ao seu contexto cultural, ao seu tempo e seu povo, passado pela oralidade. A oralidade, por sua vez, como ferramenta de registro atingiu muitos campos da vida africana que reverberam nas culturas religiosas afro-brasileiras, o que deixou como legado para a dança uma grande lacuna, quando falamos em sistematização ou mesmo em registro formal de um saber que, há muito, vem sendo repassado somente pelas vozes do corpo e do gesto.

As especificidades das danças religiosas são justamente essa trajetória que ela realiza a partir da tradição oral africana, resguardando elementos do drama ritual (homenagem aos deuses, à natureza, ao líder, ao cotidiano) e, como qualquer dança de qualquer comunidade, é representada principalmente pelos movimentos advindos dos rituais (não necessariamente os religiosos, mas sim os culturais), acompanhados por forte influência dos instrumentos e ritmos africanos. As danças de vertente religiosa podem ser entendidas e utilizadas como uma linguagem corporal socialmente contextualizada, que conta histórias, que descreve vivências, recria mundos. As danças com o caráter ritualístico ou litúrgico tem como um dos objetivos ser mais um instrumento para se atingir o transe religioso. No culto, ela é dançada pelos membros da comunidade religiosa, com seus corpos distintos e não necessariamente com treinamento específico de dança, limitando-se ao enfoque religioso e ritual do movimento dançado.

Assim, as identidades religiosas não são apagadas, elas adequam-se às tramas de poder, sendo expressadas pelos seus cânticos pois, conforme Hall (2006, p. 52), “[...] essas identidades não estão impressas em nossos genes. Entretanto nós efetivamente pensamos nelas como se fossem parte de nossa natureza essencial”. Pensando por esse viés, as identidades religiosas afro-brasileiras

\footnotetext{
${ }^{4}$ Destaco que, embora as mitologias dos(as) orixás apareçam em exemplos, como esse, elas são diferentes das dos exus e pombagiras, que são de ordens distintas. No entanto, assumem-se as "histórias das entidades" como narrativas mitológicas.

${ }^{5}$ Especificamente, rum é o maior dos atabaques e possui o registro grave; rumpi é o segundo, e possui o registro médio; e lêe é menor e possui o registro agudo. Além dos tambores, usam-se também os gãs (sinos) (MACHADO, 2014).
} 
acabam sendo definidas nos terreiros, instituições culturais. Contudo, embora haja uma desterritorialização de espaços, percebe-se uma fragmentação, na qual as identidades, produtos de uma representação no que tange a suas práticas de busca de origem, agregam símbolos como as suas músicas, cânticos, danças, entre outros. As danças, em si, trabalham com as noções identitárias.

As danças nos terreiros têm, então, papel como atividade pedagógica de educação. Segundo Nanni (2000, p. 28), “[...] a dança vem marcando presença em todos os aspectos da existência humana, seja na esfera do sagrado (rituais místicos e religiosos), seja na do profano (social e do divertimento), ou numa outra dimensão que envolva ambas as esferas". Paiva (2000), nesse sentido, propõe que o ensino da dança tenha como um de seus objetivos o de ampliar os repertórios corporais dos sujeitos. Essa constatação confirma Verderi (2000) ao enunciar que a dança não só dá a oportunidade de aquisição de habilidades, como contribui para o aprimoramento das habilidades básicas, dos padrões fundamentais e de outras potencialidades que poderão surgir.

Os terreiros constituem grupos que, pelos ritos, cantos, danças e mitologias de antepassados, adentram espaços "ditos" sagrados. Nessa lógica, as entidades, exus e pombagiras, especificamente falando, são consideradas energias, espíritos, forças oriundas da natureza (água, ar, fogo, terra e, também, matas) que corporificam reis e rainhas, cujas histórias são rememoradas por meio das danças, além de rituais específicos, a cada origem da entidade. Nas danças, os arquétipos são revividos de diferentes modos, pelos sujeitos dos terreiros, tendo em vista que cada um(a) possui, na crença religiosa, uma missão diferente na terra e, mais do que isso, para cumprir com a sua entidade. Pelas narrativas, é possível dizer que no momento das danças evidenciam-se as necessidades tanto do(a) médium, quanto da entidade, em um mesmo momento de corporeidade.

Cada movimento de dança tem sentido específico, que corporifica modos de representar as mitologias de cada exu ou pombagira que chega no terreiro. No entanto, destaca-se que, ainda que as danças possam representar as emoções de médiuns e entidades, elas não deixam de apresentar comprometimento com a história do exu ou da pomba-gira, que está chegando na terra (BASTOS, 1979). Para esse mesmo autor, a dança é, assim como expressaram os sujeitos da pesquisa, o mito ou espírito, materializado em corpos.

Dançar, então, significa, também, integrar-se com o sistema mágico-ritual (LODY, 1995), composto por músicas, gestos, expressividades condizentes com o local da manifestação. Porém, o autor destaca que, nessas danças, não há espaço para o improviso, tendo em vista que, na movimentação são reveladas partes ou o todo das identidades, das entidades. Assim, a função das danças é a de "[...] absorver o fazer implícito no próprio contexto religioso" (SANTOS, 1996, p. 36), atentando ao fato de que, a elas, não compete a aleatoriedade ou uma resposta simplista ao estímulo sonoro, mas sim, a manifestação mítica das entidades envoltas em um "[...] tecido social complexo" (SANTOS, 1996, p. 17), no qual o corpo situa-se como um "[...] instrumento de expressão, é o elemento a serviço do simbólico que revive as experiências míticas e criativas" (SANTOS, 1996, p. 18). Ao serem vistos gestos como: dançar, representar, cantar e tocar um instrumento, podemos compreender os modos como se organizam, educam e ensinam dentro dos terreiros. Desse contexto, são extraídas as expressões que falam tanto do local, quanto das entidades e, por sua vez, identidades, por ele forjado. 
Dançando conforme os pontos até que se recomecem os ritos...

Escrever sobre as danças de exus e pombagiras, a partir de terreiros de Quimbanda, da cidade do Rio Grande / RS, permitiu-nos compreender que, por entre elas, temos múltiplas redes de saber-poder que engendram saberes relacionados às manifestações culturais desse município, especificamente, acerca das religiosidades. Dentre as análises foi possível compreender que as danças apontam para modos de contar e recontar as mitologias das entidades, bem como expor rotinas dos terreiros. Além disso, destaca-se que estudar a Quimbanda praticada nessa cidade não está implicado na noção de compreender seus fundamentos, mas sim, visualizar se e como as danças ocorrem nos terreiros. Desse ponto, percebe-se que as danças correspondem aos fazeres mítico-ritualísticos dos locais da pesquisa, transpostos em gestos e expressões que conduzem tanto aqueles(as) que dançam, quanto os(as) que assistem a uma experiência religiosa que possui distintos significados, variando a produção de sentidos de um sujeito para outro.

O gestual possui significados que ora simbolizam alegrias, ora identidades e, também, momentos de insatisfação ou de batalha, pois pela sacralização do gesto, as entidades representam lutas, narrativas, histórias e enredos que intercambiam mundos - os deles(as) e o nosso, os(as) dos fiéis, segundo os sujeitos do estudo. As simbologias representam forças da natureza, de sujeitos desencarnados(as), híbridos entre animais e humanos, compondo mimeticamente expressões que variam desde olhares, sorrisos, semblantes de braveza, entre outros, chegando a passos que contemplam simbologias de afetos, abraços, carícias que, por vezes, culminam no convite para dançar com eles(as).

Pela gestualidade e relações ocorridas na tríade médiuns-entidades-assistência é possível perceber que as culturas, histórias e narrativas dos terreiros se perpetuam nos corpos dos sujeitos incorporados(as). A ocorrência simbiótica de uso do corpo do(a) médium pelas entidades possibilita a compreensão de um diálogo, nesse caso, corporal, que ocorre no jogo das aprendizagens dos terreiros e que reverbera, em forma de energia, durante a sessão. Desse modo, as recorrências aos mitos, específicos de cada entidade, produz possibilidades de danças que são características de cada exu e pombagira, aliadas aos usos dos corpos dos(as) médiuns, e que ocorre por intermédio de uma noção de educação.

Tendo a Quimbanda, como um espaço para o desenvolvimento desse estudo, pensa-se que, por meio dela e de seus saberes, analisar e compreender as danças é algo possível por diferentes razões. A primeira, por perceber nesse campo inserção das expressões das corporeidades. Segundo porque, no jogo das simbologias, as danças nos terreiros representam relação direta com a noção de identidades. E, por fim, o terceiro ponto diz respeito ao fato de que, por meio das danças e ancestralidade dos terreiros (engendrada nas mitologias das entidades e oralização), pedagogizamse os sujeitos pertencentes a esses espaços, algo possível por diferentes vieses, porém, no caso desse estudo, focalizada e percebida, especificamente, pela educação dos corpos.

\section{PASSOS QUE DANCEI...}

BARBARA, Rosamaria Susanna. A dança das Aiabás: dança, corpo e cotidiano das mulheres de candomblé. Tese de Doutorado em Sociologia. Departamento de Sociologia da Faculdade de Filosofia, Letras e Ciências Humanas. Universidade de São Paulo. São Paulo, 2002. 201p. Acesso em 20 maio 2019.

BARBOSA, Elyana. Espaço-tempo e poder-saber: uma nova epistéme? (Foucault e Bachelard). Tempo Social: Revista de Sociologia da USP, São Paulo, v. 7, n. 1-2, p. 111-120, out. 1995. Disponível em http://www.revistas.usp.br/ts/article/view/85211/88049. Acesso em 19 maio 2019. 
BASTOS, Abguar. Os cultos mágico-religiosos no Brasil. São Paulo: Hucitec, 1979.

CARDOSO, Ângelo Nonato Natale. A linguagem dos tambores. Tese de Doutorado em Música da Universidade Federal da Bahia. Salvador, 2006. Acesso em 19 maio 2019.

CONNELLY, Michel; CLANDININ, Jean. Relatos de experiência e investigação narrativa. In: LARROSA, Jorge Bondía. Déjame que te cuente. Barcelona: Ed. Laertes, 1995.

CUCHE, Denys. A noção de cultura nas Ciências Sociais. Bauru: EDUSC, 1998.

FIGUEIRA, Maria Luiza Machado. A revista Capricho e a produção de corpos adolescentes femininos. In: LOURO, Guacira Lopes; NECKEL, Jane Felipe; GOELLNER, Silvana Vilodre (orgs.). Corpo, gênero e sexualidade: um debate contemporâneo na educação. Petrópolis: Vozes, 2003. FILHO, Antônio Neves de Araújo. Protestos e manifestações afro-brasileiras na música negra baiana nos anos de 1980. Trabalho de Conclusão de Curso (Especialização em História e Cultura Africana e AfroBrasileira), Universidade Federal do Rio Grande do Norte, Centro de Ensino Superior do Seridó, Campus de Caicó. 2016. 50f. Acesso em 27 maio 2019.

FLICK, Uwe. Uma introdução à pesquisa qualitativa. Tradução de Joice Elias Costa. 3. ed. Porto Alegre: Artmed, 2009.

FOUCAULT, Michel. História da sexualidade III: o cuidado de si. v. 3. Rio de Janeiro: Graal, 2007b. FOUCAULT, Michel. Vigiar e punir. Petrópolis: Vozes, 1997a.

FOUCAULT, Michel. O sujeito e o poder. In: DREYFUS, Hubert L.; RABINOW, Paul. Michel Foucault, uma trajetória filosófica: para além do estruturalismo e da hermenêutica. Rio de Janeiro: Forense Universitária, 1995.

GUERRA, Denise. Um olhar sobre a cultura corporal de movimento afro-brasileira construída a partir da corporeidade africana. Revista África e Africanidades. Ano I, n. 2, ago. 2008, p. 1-6. Disponível http://www.africaeafricanidades.com.br/documentos/um olhar sobre a cultura corporal de movimento_afro_brasileiro.pdf. Acesso em 26 maio 2019.

GUERREIRO, Goli. A trama dos tambores: a música afro-pop de Salvador. 2. ed. São Paulo: Ed. 34, 2010. (Coleção Todos os Cantos).

GIANNATTASIO, Gabriel. O corpo em Sade e Nietæsche: ou, quem sou eu agora? [Ensaios] Gabriel Giannattasio. Londrina: EDUEL, 2012.

GOELLNER, Silvana Vilodre. A educação dos corpos, dos gêneros e das sexualidades e o reconhecimento da diversidade. Cadernos de formação RBCE - Revista Brasileira de Ciências do Esporte, p. 71-83, mar. 2010. Disponível em http://revista.cbce.org.br/index.php/cadernos/article/view/984. Acesso em 20 jan. 2019.

GOELLNER, Silvana Vilodre. A produção cultural do corpo. In: LOURO, Guacira Lopes (org.). Corpo, gênero e sexualidade: um debate contemporâneo na educação. 3. ed. Petrópolis: Vozes, 2007.

HALL, Stuart. A identidade cultural na pós-modernidade. Tradução de Tomaz Tadeu da Silva e Guacira Lopes Louro. 11. ed. Rio de Janeiro: DP\&A, 2006.

LE BRETON, David. A sociologia do corpo. Petrópolis: Vozes, 2006.

LE BRETON, David. Adeus ao corpo: antropologia e sociedade. Campinas, São Paulo: Papirus, 2003. LODY, Raul. O povo do santo: religião, história e cultura dos orixás, voduns, inquices e caboclos. Rio de Janeiro: Pallas, 1995.

MACHADO, Felipe. Entre rodas de dança e coreografias: notas para um pensamento dançarino. p. 15-23. Horizonte de la Ciencia. v. 4 (n. 7), diciembre 2014. Acesso em 21 jan. 2019.

MACHADO, Roberto. Foucault, a ciência e o saber. Rio de Janeiro: Jorge Zahar, 2006. 
MIRANDA, Eduardo Oliveira. O negro do Pomba quando sai da Rua Nova, ele traz na cinta uma cobra coral: os desenhos dos corpos-territórios evidenciados pelo Afoxé Pomba de Malê. Dissertação (mestrado) - Universidade Estadual de Feira de Santana - Programa de Pós-Graduação em Desenho, Cultura e Interatividade. Feira de Santana, 2014. 168f. Acesso em 28 jan. 2019.

NANNI, Dionísia. O ensino da dança na estruturação/expansão da consciência corporal e da autoestima do educando. Revista Mineira de Educaşão Física de Viçosa. 2000, n. 8, p. 27-43.

NELSON, Cary; TREICHLER, Paula; GROSSBERG, Lawrence. Estudos culturais: uma introdução. In: SILVA, Tomaz Tadeu da (org.) Alienigenas na sala de aula: uma introdução aos estudos culturais em educação. Rio de Janeiro: Vozes, 1995. p. 7-38.

ORTEGA, Francisco. Das utopias sociais às utopias corporais: identidades somáticas e marcas corporais. In: ALMEIDA, Maria Isabel Mendes de; EUGÊNIO, Fernanda (orgs.). Culturas jovens: novos mapas do afeto. Rio de Janeiro: Jorge Zahar Ed., 2006.

PAIVA, Maria Aparecida. Construindo a dança na escola. [Monografia do Curso de Pós-graduação em Dança-Educação]. Rio de Janeiro: Universidade Federal do Rio de Janeiro (UFRJ), 2000.

QUADRADO, Raquel Pereira. Corpos híbridos: problematizando as representações de corpos no currículo escolar. In: RIBEIRO, Paula Regina Costa (org.). Corpos, gêneros e sexualidades: questões possíveis para o currículo escolar. Caderno Pedagógico Anos Iniciais. Rio Grande: FURG, 2007.

SANTIN, Silvino. Educação física: uma abordagem filosófica da corporeidade. 2. ed. Ijuí: Ed. Unijuí, 2003.

SANTOS, Inaicyra Falcão dos. Da tradição africana a uma proposta pluricultural de dança-arte-educação. 1996. Tese (Doutorado em Educação) - Faculdade de Educação, Universidade de São Paulo, São Paulo.

SOARES, Rodrigo Lemos; DILLMANN, Mauro. Narrativas históricas: ensaiando movimentações de exus e pombagiras em terreiros de Quimbanda de Rio Grande / Rio Grande do Sul. Educação. Santa Maria. v. 45, 2020.

SOARES, Rodrigo Lemos. Dançando cultura: saberes coreografados sobre a Festa de Iemanjá no município do Rio Grande / Rio Grande do Sul. Revista Teias, [s. 1.], v. 19, n. 53, p. 129-142, jul. 2018. Disponível em https://www.epublicacoes.uerj.br/index.php/revistateias/article/view/34047/25270. Acesso em 20 jul. 2020.

SOUZA, Edilson Fernandes. Etnografia e história da dança litúrgica e artística no Rio de Janeiro. In. Anais. VII Congresso brasileiro de história da Educação Física, esportes, lazer e dança (Gramado - Rio Grande do Sul). Porto Alegre: UFRGS/ESEF, 2000. p. 304-308. Disponível em https://lume.ufrgs.br/handle/10183/99134. Acesso em 27 jan. 2019.

STRAZZACAPPA, Marcia. A educação e a fábrica de corpos: a dança na escola. Cadernos CEDES, Campinas, v. 21, n. 53, p. 69-83, abr. 2001.

VERDERI, Érica Beatriz Lemes Pimentel. Dança na escola. 2. ed. Rio de Janeiro: Sprint, 2000. 


\section{Informações dos autores}

Rodrigo Lemos Soares

Programa de Pós-graduação em Educação - Doutorado/ Universidade Federal de Pelotas, Faculdade de Educação; Grupo Interdisciplinar de Pesquisa: Narrativas, Arte, Linguagem e Subjetividade (GIPNALS) e Grupo Paisagens Híbridas (UFRJ)

E-mail: rodrigosoaresfurg@gmail.com

ORCID: https://orcid.org/0000-0002-1690-8991

Link Lattes: http://lattes.cnpq.br/7158430253302821

Mauro Dillmann

Professor Adjunto no Departamento de História e no Programa de Pós-graduação em História da Universidade Federal de Pelotas (UFPEL).

E-mail: maurodillmann@,hotmail.com

ORCID: https://orcid.org/0000-0002-8315-7788

Link Lattes: http://lattes.cnpq.br/5567003394621139 